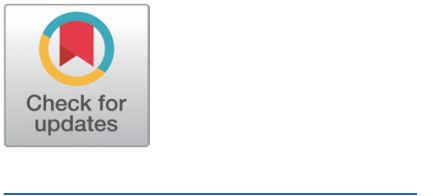

Received: Apr 13, 2021

Revised: Apr 20, 2021

Accepted: Apr 21, 2021

*Corresponding author Jeehwan Choe

Department of Beef Science, Korea National College of Agriculture and

Fisheries, Jeonju 54874, Korea.

Tel: +82-63-238-9215

E-mail: choejhw@gmail.com

Copyright ( 2021 Korean Society of Animal Sciences and Technology.

This is an Open Access article distributed under the terms of the Creative Commons Attribution Non-Commercial License (http:// creativecommons.org/licenses/by$\mathrm{nc} / 4.0 /$ ) which permits unrestricted non-commercial use, distribution, and reproduction in any medium, provided the original work is properly cited.

ORCID

Chun Ho Park

https://orcid.org/0000-0002-5609-4320

Hye Sook Park

https://orcid.org/0000-0001-9629-9673

Kyungah Yoon

https://orcid.org/0000-0002-4638-5714

Jeehwan Choe

https://orcid.org/0000-0002-7217-972X

Competing interests

No potential conflict of interest relevant to this article was reported.

Funding sources

This paper was supported by Daejeon Health Institute of Technology in 2018.

\section{Changes in the quality of pork loin after short-term (ten-day) storage in a supercooling refrigerator}

\author{
Chun Ho Park ${ }^{1}$, Hye Sook Park², Kyungah Yoon ${ }^{3}$ and Jeehwan Choe ${ }^{4 *}$ \\ ${ }^{1}$ Department of Hotel \& Food Service Culinary Art, Daejeon Health Institute of Technology, Daejeon \\ 34504, Korea \\ ${ }^{2}$ Department of Environmental Health, Daejeon Health Institute of Technology, Daejeon 34504, Korea \\ ${ }^{3}$ Department of Clinical Laboratory Science, Daejeon Health Institute of Technology, Daejeon 34504, \\ Korea \\ ${ }^{4}$ Department of Beef Science, Korea National College of Agriculture and Fisheries, Jeonju 54874, Korea
}

\begin{abstract}
The study aimed to evaluate pork loin quality after short-term (ten-day) storage in a supercooling refrigerator. Pork loin samples were stored for 10 days in a traditional refrigerator (control) and a commercially available supercooling refrigerator (SC). Pork quality measurements included meat $\mathrm{pH}$, meat color, water holding capacity (drip loss and cooking loss), tenderness (hardness), and a sensory evaluation. Temperature changes of $0.45 \pm 0.2^{\circ} \mathrm{C}$ and $0.02 \pm 0.25^{\circ} \mathrm{C}$ occurred in the control and the SC, respectively, during 10 days of storage. The temperature in the $\mathrm{SC}$ chamber did not remain below freezing point, failing to meet expectations. Regarding the pork quality measurements, only the drip losses in the control and the SC were significantly different $(4.45 \%$ vs. $2.59 \%, p<0.01)$ after 10 days of storage. There were no significant differences between the two types of refrigerator in terms of the other measurements. Additionally, the overall acceptability of the pork loin did not vary significantly between the control and the SC when the sensory evaluation was performed. Therefore, a commercial SC could prove beneficial in terms of water holding capacity during the shortterm storage of meat. Further research should be performed to evaluate quality changes that occur during long-term storage of meat in SC $\mathrm{s}$ and evaluate a wide range of meat, such as beef and chicken.
\end{abstract}

Keywords: Supercooling, Short-term storage, Pork, Drip loss

\section{INTRODUCTION}

Freshness is one of the most important indicators to consumers purchasing meat [1]. Consumers have increased their demands in terms of eating satisfaction and safety against microbial and disease hazards in fresh meat [1]. In general, meats are extremely perishable due to favorable growth conditions for microorganisms and the reactions of chemical components and enzymes [2]. Spoiled meat is not safe for consumption due to microbial growth and deterioration of quality [2]. Thus, preservation techniques to increase the shelf life and maintain the quality of meat in term of color, texture, and flavor are important. 
Acknowledgements

Not applicable.

Availability of data and material Upon reasonable request, the datasets of this study can be available from the corresponding author.

Authors' contributions

Conceptualization: Park $\mathrm{CH}$, Park HS, Yoon K, Choe J.

Data curation: Park CH, Park HS, Yoon K, Choe J.

Formal analysis: Park CH, Park HS, Yoon K, Choe J.

Methodology: Park CH, Park HS, Yoon K, Choe J.

Software: Park $\mathrm{CH}$, Choe J.

Validation: Park CH, Park HS, Yoon K, Choe J. Investigation: Park $\mathrm{CH}$, Park HS, Yoon K, Choe J.

Writing - original draft: Park $\mathrm{CH}$, Choe J. Writing - review \& editing: Park CH, Park HS, Yoon K, Choe J.

Ethics approval and consent to participate This article does not require IRB/IACUC approval because there are no human and animal participants.
Various techniques have been developed for preserving meats. Salting, drying, smoking, fermentation, and canning are traditionally used to prevent meat spoilage and to extend shelf life [2]. However, preserving meat with these methods can change its freshness, composition, and quality. Refrigeration can also be used to preserve meat and meat products. Refrigeration retards or limits the spoilage rate of meats by inhibiting the microbial growth and chemical and enzymatic reactions while minimizing changes of meat freshness, composition, nutritive values, and quality traits [3]. Refrigeration can be conducted at three basic temperature levels: cooling, freezing, and supercooling $[2,3]$. The cooling and freezing methods use temperature levels above and below the freezing point, respectively. Freezing is relatively critical for prolonging the shelf life of meat compared to cooling, but the formation of ice crystals during freezing is one of its disadvantages. Ice crystal formation disrupts the microstructures in meat and results in moisture loss (drip loss), leading to nutritive and sensorial losses upon thawing. Greater drip loss is inevitable during the freezing-thawing process compared to the cooling method, although the amount of drip loss during thawing depends on the rate of freezing and thawing and the method used for thawing [3-5].

The supercooling method decreases the internal temperature of meat to below its freezing point before ice crystal can form [6-8] and, at the same time, slowing or inhibiting microbial growth and chemical and enzymatic activities [6,7]. Thus, the supercooling method is used to for perishable foods prone to quick spoilage, especially fish and meat [3,6-8]. However, the supercooling method must feature strict temperature control because any temperature fluctuations during storage can result in ice crystal formation $[6,7,9]$.

Recently, commercial supercooling refrigerators heave been developed for drinks. This type of refrigerator is cooled by chilled air circulation by multiple fans, resulting in chilled air that moves evenly throughout the chamber. We hypothesized that their chilling mechanisms could help improve the freshness of meat. Thus, as a first step, we evaluated the quality of pork loin after shortterm (ten-day) storage in one of these supercooling refrigerators.

\section{MATERIALS AND METHODS}

\section{Pork preparation and storage procedure}

Pork loins were purchased from a local meat producer $24 \mathrm{~h}$ after slaughter. Pork samples were moved from the market to the laboratory in a cooling box with a controlled temperature $\left(2-4^{\circ} \mathrm{C}\right)$. Pork loins were cut into 20-mm-thick steaks. Each steak was packaged in its own plastic box and sealed with polyvinyl wrapping. The samples were randomly distributed between the two treatments, namely, a conventional refrigerator (control, KSR-462RR, Kumwon Hi-Tech, Paju, Korea) and a supercooling refrigerator (SC, SC40-11PGRD, South Valley, Cheonan, Korea). The temperature controls were set at $0{ }^{\circ} \mathrm{C}$ and $-0.5^{\circ} \mathrm{C}$ for control and SC, respectively. During sample storage, auto-recoding thermometers (testo $174 \mathrm{~T}$, Testo SE \& Co. KGaA, Lenzkirch, Germany) were used to monitor internal temperature changes in the refrigerators.

\section{Pork quality measurements}

All pork quality traits were measured in triplicate on days 0 and 10 . Any frozen samples were not included in the quality measurements.

Meat $\mathrm{pH}$ was measured directly using a portable $\mathrm{pH}$ meter (testo $206 \mathrm{pH} 2$, Testo SE \& Co. $\mathrm{KGaA}$ ) designed for meat. The $\mathrm{pH}$ meter has a built-in temperature compensation system.

Meat color was measured using Minolta Chroma meter (CR-400, Konica Minolta, Tokyo, Japan) [10]. The samples were put on the table for 20 min without any packaging to allow contact with the air (for the bloom). Each measurement was done in triplicate. The color of each sample 
was expressed as Commission Internationale de l'Eclairage (CIE) lightness, redness, and yellowness.

Water holding capacity (WHC) was measured as both drip loss from uncooked samples and cooking loss from cooked samples [10]. Briefly, the samples used for drip loss measurements were cut from the pork steaks and weighed immediately (initial weight for drip loss measurement). The samples were placed in an inflated bag that was impermeable to air and moisture. There was no contact between the samples and bag. The samples were taken from the bag after $48 \mathrm{~h}$ of storage at $4^{\circ} \mathrm{C}$. Their surface moisture was removed gently, and then they were weighed again (final weight for drip loss measurement). Drip loss was calculated as the percentage difference between the initial sample weight and the final sample weight. The samples used for cooking loss measurements were cut for the pork steaks and weighed (initial weight for cooking loss measurement). The samples were put in airless, thin-walled polyethylene bags and then placed in a continuously boiling water bath. The samples were considered to be cooked when their internal temperature reached $75^{\circ} \mathrm{C}$. At $75^{\circ} \mathrm{C}$, the bags were taken out of the water bath, cooled in an ice slurry, and kept under chilled conditions $\left(1-5^{\circ} \mathrm{C}\right)$ until equilibration. Then the samples were removed from their bags, dried gently, and weighed again (final weight for cooking loss measurement). Cooking loss was calculated as the percentage difference between the initial sample weight and the final sample weight.

Texture profile analysis (TPA) was performed to determine hardness as a tenderness measurement [11]. Samples were prepared for the hardness measurement the same way they were prepared for the cooking loss measurement. After equilibrium was achieved, the surfaces of the cooked samples were removed, and the pork chops were cut into $15-\mathrm{mm}$ cubes with parallel to the fiber direction. A texture analyzer (TAXT2i, Stable Micro System, Surrey, UK) was used for TPA measurement. The fiber axis of each cube sample was placed perpendicular to the direction of a cylindrical probe (10 $\mathrm{mm}$ in a diameter). The probe moved down toward the samples at constant speeds of $3.0 \mathrm{~mm} / \mathrm{s}$ (pre-test), $1.0 \mathrm{~mm} / \mathrm{s}$ (test) and $3.0 \mathrm{~mm} / \mathrm{s}$ (post-test). It penetrated a predetermined percentage $(75 \%)$ of the sample thickness, came back to the initial point of contact with each sample, then stopped for a set time period ( $2 \mathrm{~s}$ ) before beginning a second compression cycle. The force value was recorded every $0.01 \mathrm{~s}$ and plotted on a force-time plot [12]. The hardness of each sample was obtained as the highest value during the first compression cycle [10,11,13]. At least six pieces were tested to calculate the mean hardness value of each sample.

\section{Sensory evaluation (hedonic test)}

Sensory evaluations of the cooked samples were performed. Each steak was roasted in an oven (MCS312CF4, Electrolux, Stockholm, Sweden) pre-heated to $180^{\circ} \mathrm{C}$ while being turned every 3 min until its internal temperature reached $72^{\circ} \mathrm{C}$. The internal temperature was measured using a hand-held probe thermometer (TES-1300, TES Electrical Electronic, Taipei, Taiwan). The cooked steaks were cut into $15 \mathrm{~mm}$ cubes, placed on white plastic trays covered with aluminum foil, and served immediately to a panel of 20 graduate students. Each sample was evaluated at least three times by each panel. The cooked samples were evaluated using unstructured line scales for color $(1=$ very unacceptable; 5 = very acceptable), flavor $(1=$ very unacceptable; $5=$ very acceptable $)$, off-flavor ( 1 = very strong; 5 = very weak $)$, texture $(1=$ very unacceptable; 5 = very acceptable $)$, tenderness $(1=$ very tough; 5 = very tender), and overall acceptability ( $1=$ very unacceptable; 5 = very acceptable).

\section{Statistical analysis}

Statistical analysis was performed via one-way analysis of variance (ANOVA) procedure available in SAS software v. 9.4 (SAS Institute, Cary, NC, USA). Results were expressed as means and standard deviations. Significant differences in means were detected for $p<0.05$. 


\section{RESULTS AND DISCUSSION}

Supercooling and superchilling inhibit microbial growth and chemical and enzymatic reactions by lowering the temperature and minimizing damages due to no ice crystal formation or small size of ice crystal [7]. Superchilling cools food rapidly until its internal temperature reaches approximately $1-2{ }^{\circ} \mathrm{C}$ below its freezing point. During the process, some water converts to ice, thus superchilling is also called partial freezing $[3,7,9]$. In contrast, supercooled state can be achieved when the food's internal temperature is below its freezing point without ice crystal formation [6,7]. The important point of supercooling is that there is no ice crystals. Because supercooled food is very unstable, any physical vibration or small temperature fluctuations during storage can cause ice to crystallize [7]. Therefore, supercooling temperature must be strictly controlled. Hence, supercooling is most suitable for premium foods, and most of the research has been done on superchilling as opposed to supercooling $[7,8,14]$.

First, we measured the temperature inside the refrigerators during storage to check temperature stability (Fig. 1). The temperature was relatively well controlled at the set temperature for both the control $\left(0.45 \pm 0.2^{\circ} \mathrm{C}\right)$ and the $\mathrm{SC}\left(0.02 \pm 0.25^{\circ} \mathrm{C}\right)$. In particular, there was no significant temperature fluctuation during supercooling storage, preventing the formation of ice crystals.

Next, we measured the quality of the pork loin after short-term (ten-day) storage for both the control and the SC. There was no difference note in meat $\mathrm{pH}$ between the control and the SC on days 0 and 10 (Fig. 2). Generally, meat $\mathrm{pH}$ decreases gradually after slaughter until rigor

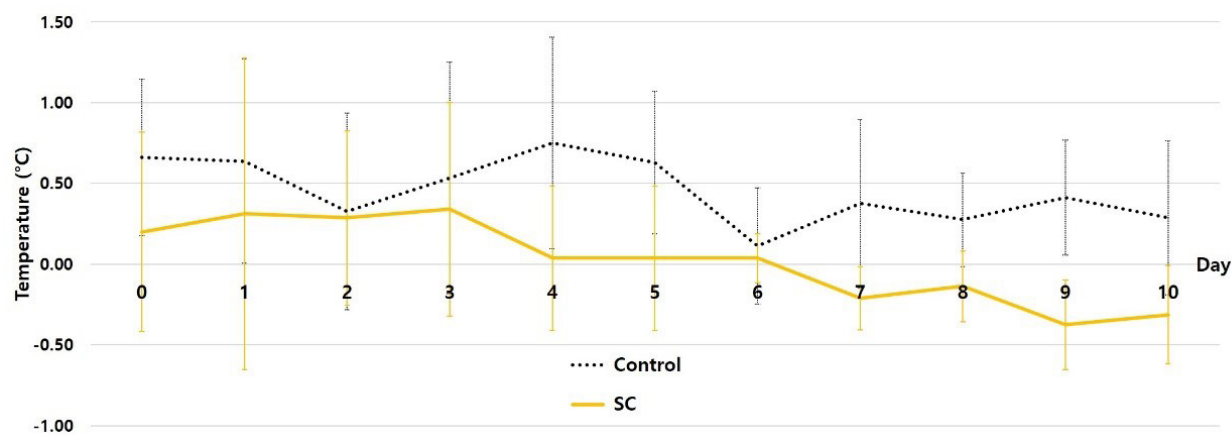

Fig. 1. Temperature changes in the control and supercooling refrigerators during the short-term (10-day) storage period. Control, a traditional refrigerator; SC, supercooling refrigerator.

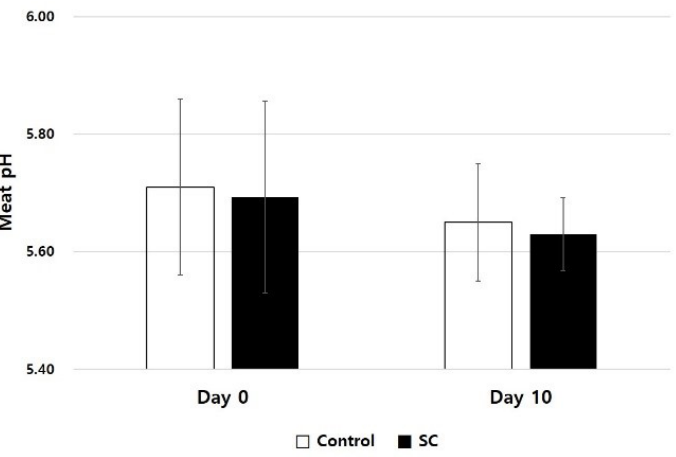

Fig. 2. Meat pH of pork loins after short-term (10-day) storage in the control and supercooling refrigerators. Three samples $(n=3)$ were used for each treatment. Data are presented as mean values with standard deviation bars. Control, a traditional refrigerator; SC, supercooling refrigerator. 
mortis has done [5]. Some studies have shown that meat $\mathrm{pH}$ increases during low-temperature storage $[15,16]$. In those studies, pork loins were stored at temperature below $0^{\circ} \mathrm{C}[16]$ or under superchilling condition [15] for periods greater than 10 days. In this research, there was no increase in meat $\mathrm{pH}$ from day 0 to day 10 , regardless of storage conditions.

Meat color did not differ significantly between the control and the $\mathrm{SC}$ on days 0 and 10 (Fig. $3)$. Lightness $(p<0.001)$ and yellowness $(p<0.01)$ increased significantly after 10 days of storage. Meat color is affected significantly by the denaturation and chemical state of myoglobin $[4,5]$. Myoglobin is composed of two parts, the globin protein and heme ring. The denaturation of globin during storage increases myoglobin's susceptibility to oxidation, leading to optimum color loss [4]. Additionally, all types of oxidation, including lipid and protein oxidation, may be associated with myoglobin oxidation. Thus, lipid and protein oxidation caused by storage result in pro-oxidant formations that can react with myoglobin, leading to metmyoglobin formation $[4,17]$. In this study, the acid value, as an indicator of oxidation, for the control and the $\mathrm{SC}$ was not significantly different (data not provided). Thus, short-term storage may not lead to the severe denaturation of globin and oxidation of lipid and protein, subsequently the meat color may not have been affected strongly.

Drip loss, used to measure the WHC of uncooked meat, was statistically different at 10 days of storage (4.45 vs. $2.59, p<0.01$; see Fig. 4 ) for the control and the SC. The water fraction of meat is a main concern when considering the low-temperature storage of meat, especially when stored under its freezing point. Storage below the freezing point inhibits microbial growth and enzymatic and chemical reactions, resulting in prolonged display and selling periods [2,3,6-8]. At the same

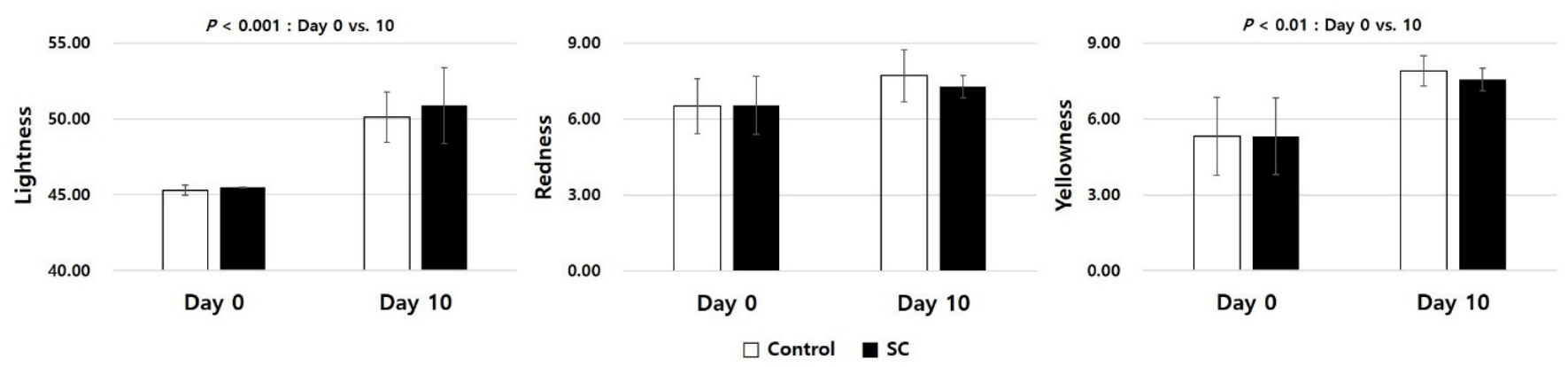

Fig. 3. Meat color of pork loins after short-term (10-day) storage in the control and supercooling refrigerators. Three samples $(n=3)$ were used for each treatment. The meat color of each sample was measured in triplicate. Meat color is presented as CIE $\mathrm{L}^{*}$, CIE $a^{*}$, and $\mathrm{CIE} b^{*}$. Data are presented as mean values with standard deviation bars. Control, a traditional refrigerator; SC, supercooling refrigerator.

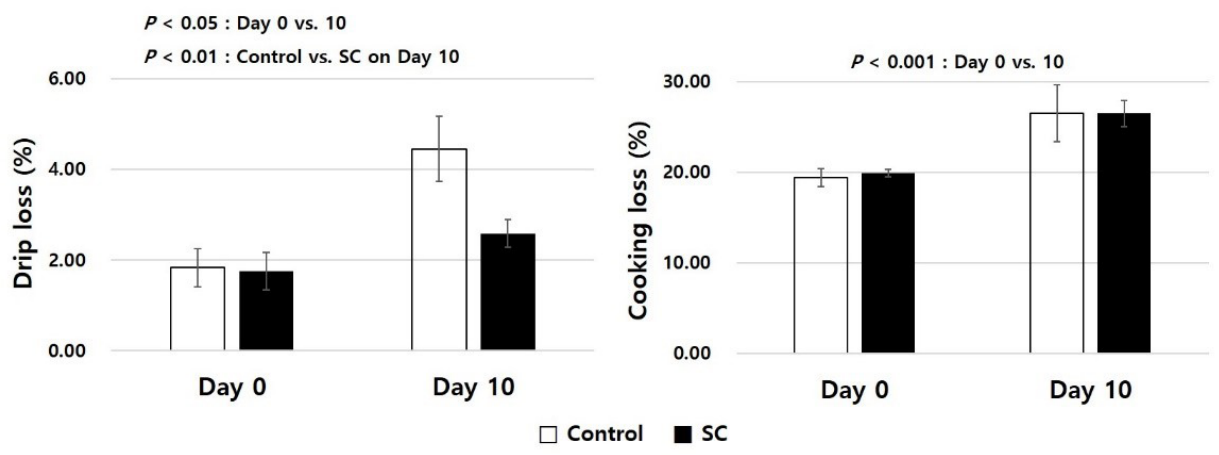

Fig. 4. Drip loss and cooking loss of pork loins after short-term (10-day) storage in the control and supercooling refrigerators. Three samples $(n=3)$ were used for each treatment. Data are presented as mean values with standard deviation bars. Control, a traditional refrigerator; SC, supercooling refrigerator. 
time, ice crystal formation can disrupt the structural integrity of meat and cause changes in the muscle cell membranes via increase in the solute concentration, leading to increases in drip loss and thawing loss $[3,4,6-8,18,19]$.

The supercooling and superchilling methods overcome the disadvantages of freezing while maintaining its advantages. They can increase the shelf life of meat by retarding microbial growth and enzymatic and chemical reactions while maintaining structural integrity (supercooling) or minimizing the changes in the microstructure (superchilling) [2-4,6-8,15]. No significant difference was found in drip loss between supercooling and refrigeration of beef steak until 7 days of storage [6]. After, supercooled beef steak had lower drip loss than refrigerated beef steak on day 14 [6]. A study on pork quality found that the drip loss for superchilled pork was lower than that achieved through standard chilling and temperature abused superchilling [15]. In addition, superchilled pork entrapped more water than pork stored under other conditions [15]. However, cooking loss, a measurement of the WHC of cooked meat, did not differ when comparing short-

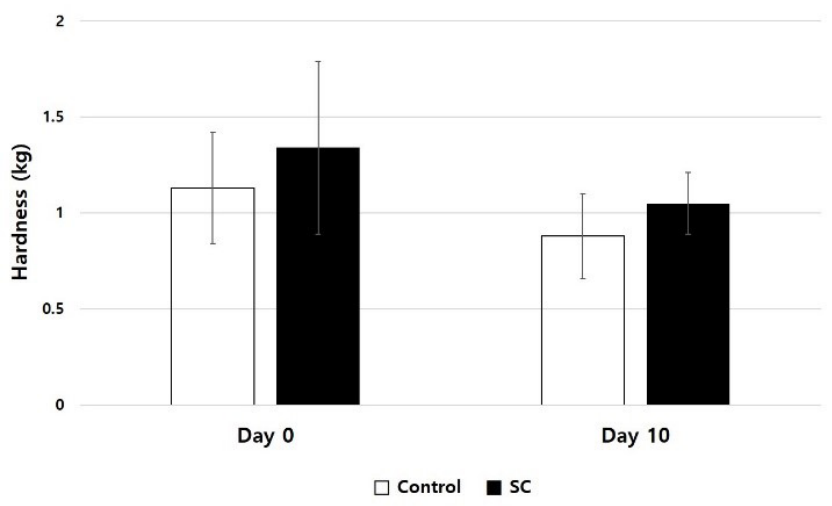

Fig. 5. Hardness of pork loins after short-term (10-day) storage in the control and supercooling refrigerators. Three samples $(n=3)$ were used for each treatment. Hardness of each sample was measured at least six times. Data are presented mean values with standard deviation bars. Control, a traditional refrigerator; $\mathrm{SC}$, supercooling refrigerator.

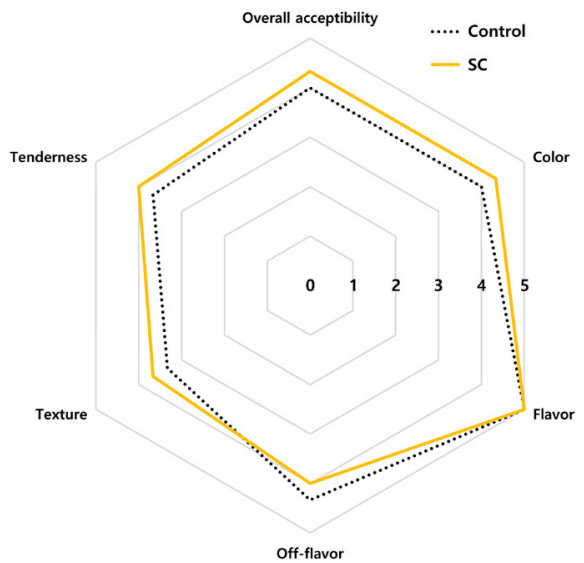

Fig. 6. Sensory evaluation of pork loins after short-term (10-day) storage in the control and supercooling refrigerators. Twenty panelists evaluated the cooked samples. Each sample was evaluated at least three times by each panel. The cooked samples were evaluated using unstructured line scales for color $(1=$ very unacceptable; $5=$ very acceptable), flavor ( $1=$ very unacceptable; $5=$ very acceptable), off-flavor $(1=$ very strong; $5=$ very weak $)$, texture $(1=$ very unacceptable; $5=$ very acceptable $)$, tenderness $(1=$ very tough; 5 $=$ very tender $)$, and overall acceptability $(1=$ very unacceptable; $5=$ very acceptable $)$. Control, a traditional refrigerator; SC, supercooling refrigerator. 
term storage treatments in the current study. Unlike our result, different cooking loss values were obtained for different superchilling temperatures [20]. The differences in result between the current study and Ding et al. [20] may be attributed to the storage methods (supercooling vs. superchilling) and storage temperatures (approximately $0^{\circ} \mathrm{C}$ vs. $-1^{\circ} \mathrm{C},-2^{\circ} \mathrm{C}$, and $-3^{\circ} \mathrm{C}$ ).

We used the TPA method to measure tenderness via hardness value [11]. There was no difference in hardness between the control and the SC on days 0 and 10 (Fig. 5). Tenderness, or the texture of meat, is associated with various factors, such as WHC, fat content, connective tissue content, and so on $[5,11]$. Although supercooled pork loin had significantly lower drip loss than the control pork loin in the current study, this lower drip loss may not affect the hardness measured by TPA. Similarly, there were no significant differences between the storage methods for the sensory evaluation items including color, flavor, off-flavor, texture, and tenderness (Fig. 6).

Therefore, pork loin stored in a SC for 10 days benefitted from lower drip loss than pork loin stored in a traditional refrigerator. However, there was no significant differences noted for other quality measurements after short-term storage. This research presents a first step in evaluating the potential uses of the commercial SCs for meat preservation. Further research should be performed to evaluate the quality of pork loin stored long-term (more than 30 days) in a $\mathrm{SC}$ and to evaluate other meats, such as beef and chicken.

\section{REFERENCES}

1. Glitsch K. Consumer perceptions of fresh meat quality: cross-national comparison. Br Food J. 2000;102:177-94. https://doi.org/10.1108/00070700010332278

2. Dave $\mathrm{D}$, Ghaly $\mathrm{AE}$. Meat spoilage mechanisms and preservation techniques: a critical review. Am J Agric Biol Sci. 2011;6:486-510. https://doi.org/10.3844/ajabssp.2011.486.510

3. Zhou GH, Xu XL, Liu Y. Preservation technologies for fresh meat: a review. Meat Sci. 2010;86:119-28. https://doi.org/10.1016/j.meatsci.2010.04.033

4. Leygonie C, Britz TJ, Hoffman LC. Impact of freezing and thawing on the quality of meat: review. Meat Sci. 2012;91:93-8. https://doi.org/10.1016/j.meatsci.2012.01.013

5. Aberle ED, Forrest JC, Gerrard DE, Mills EW. Principles of meat science. Dubuque, IA: Kendall Hunt; 2012.

6. You Y, Her JY, Shafel T, Kang T, Jun S. Supercooling preservation on quality of beef steak. J Food Eng. 2020;274:109840.

7. Shafel T, Lee SH, Jun S. Food preservation technology at subzero temperatures: a review.J Biosyst Eng. 2015;40:261-70. https://doi.org/10.5307/JBE.2015.40.3.261

8. Stonehouse GG, Evans JA. The use of supercooling for fresh foods: a review. J Food Eng. 2015;148:74-9. https://doi.org/10.1016/j.jfoodeng.2014.08.007

9. Banerjee R, Maheswarappa NB. Superchilling of muscle foods: potential alternative for chilling and freezing. Crit Rev Food Sci Nutr. 2019;59:1256-63. https://doi.org/10.1080/10408398.20 17.1401975

10. Honikel KO. Reference methods for the assessment of physical characteristics of meat. Meat Sci. 1998;49:447-57.https://doi.org/10.1016/S0309-1740(98)00034-5

11. Choe JH, Choi MH, Rhee MS, Kim BC. Estimation of sensory pork loin tenderness using Warner-Bratzler shear force and texture profile analysis measurements. Asian-Australas J Anim Sci. 2016;29:1029-36. https://doi.org/10.5713/ajas.15.0482

12. de Huidobro FR, Miguel E, Blázquez B, Onega E. A comparison between two methods (Warner-Bratzler and texture profile analysis) for testing either raw meat or cooked meat. Meat Sci. 2005;69:527-36. https://doi.org/10.1016/j.meatsci.2004.09.008 
13. Bourne MC. Texture profile analysis. Food Technol. 1978;32:62-6,72.

14. Fukuma Y, Yamane A, Itoh T, Tsukamasa Y, Ando M. Application of supercooling to longterm storage of fish meat. Fisheries Sci. 2012;78:451-61. https://doi.org/10.1007/s12562-0110460-6

15. Duun AS, Hemmingsen AKT, Haugland A, Rustad T. Quality changes during superchilled storage of pork roast. LWT-Food Sci Technol. 2008;41:2136-43. https://doi.org/10.1016/ j.lwt.2008.02.001

16. Holley RA, Peirson MD, Lam J, Tan KB. Microbial profiles of commercial, vacuum-packaged, fresh pork of normal or short storage life. Int J Food Microbiol. 2004;97:53-62. https://doi. org/10.1016/j.ijfoodmicro.2004.03.029

17. Farouk MM, Swan JE. Effect of muscle condition before freezing and simulated chemical changes during frozen storage on the $\mathrm{pH}$ and colour of beef. Meat Sci. 1998;50:245-56. https://doi.org/10.1016/S0309-1740(98)00036-9

18. Landerslev MG, Araya-Morice A, Pomponio L, Ruiz-Carrascal J. Weight loss in superchilled pork as affected by cooling rate. J Food Eng. 2018;219:25-8. https://doi.org/10.1016/j.jfoodeng.2017.09.012

19. Lawrie RA, Ledward D. Lawrie's meat science. 7th ed. Kent, UK: Woodhead; 2006.

20. Ding D, Zhou C, Ge X, Ye K, Wang P, Bai Y, et al. The effect of different degrees of superchilling on shelf life and quality of pork during storage.J Food Process Preserv. 2020;44:e14394. https://doi.org/10.1111/jfpp.14394 